\title{
Optimization of Mine Down-Hole Equipment Maintenance Strategy based on Fault Data
}

\author{
Zhenzhen Jin ${ }^{\mathrm{a}}$, Qinghe Yuan ${ }^{\mathrm{a},}$, Yingqian Sun ${ }^{\mathrm{a}}$, Shun Jia ${ }^{\mathrm{a}}$, and Zhaojun $\mathrm{Li}^{\mathrm{a}}$ b \\ ${ }^{a}$ Mining and Safety Engineering College, Shandong University of Science and Technology, Qingdao, 266590, China \\ ${ }^{b}$ Department of Industrial Engineering and Engineering Management, Western New England University, Springfield, Massachusetts, 01119, USA
}

\begin{abstract}
Aiming at the problems of poor operating conditions, low operating efficiency, and improper maintenance of mine down-hole equipment, a new maintenance strategy model for cycle prevention is proposed. The model comprehensively considers the effect of down-hole environment on the equipment failure rate and the effect of preventive maintenance and minor repairs to the cost. Based on the historical fault data, the equipment failure rate function parameters are estimated by the least square method and correlation coefficient method. Considering the down-hole environment, the fuzzy rate theory is used to correct the failure rate function, and the cycle prevention maintenance strategy model aiming at optimizing the equipment maintenance cost is established. Finally, an example is given. The research shows that the maintenance period is shortened to $23.64 \mathrm{~h}$ after optimization, and the total cost of maintenance is reduced from 574,621 yuan to $378,942.44$ yuan, saving maintenance costs of $195,678.56$ yuan. The maintenance strategy is in line with the actual situation of down-hole equipment in mining enterprises, and it can provide effective maintenance solutions for down-hole equipment in mine enterprises.
\end{abstract}

Keywords: down-hole equipment; preventive maintenance; fuzzy theory; minor repair cost

(Submitted on September 8, 2019; Revised on September 20, 2019; Accepted on September 25, 2019)

(C) 2019 Totem Publisher, Inc. All rights reserved.

\section{Introduction}

Mine down-hole equipment is an important pillar for the production and operation of mining enterprises. Its stable operation is the core of the efficient production of the whole mining enterprise, and the maintenance of equipment is the basis to ensure the smooth operation of equipment. Therefore, how to make reasonable maintenance strategies according to the status of equipment becomes crucial. Many scholars at home and abroad have studied this. Vagenas proposed a maintenance method for mining equipment. Based on the maintenance data of the equipment, a graphical method was used to create a failure trend chart to analyze the failure trend of the loader, and the reliability of the loader was evaluated based on the analyzed failure trend. By comparing the fitting degree of the Weibull distribution, exponential distribution, and log-normal distribution to the fault interval time, the proper distribution model was determined, and the average fault interval time was determined as the preventive maintenance time of the loader [1]. By analyzing the fault data of the subsystem of the shovel machine, Samanat determined the fault data according to the Weibull distribution model of two parameters and identified the fundamental cause of the failure of each subsystem through fault analysis. Finally, through the reliability function of the two-parameter Weibull distribution model, the time interval of preventive maintenance for each subsystem was determined [2]. Hall first identified the prominent problem of hydraulic shovel faults through pareto analysis, conducted failure mode and effects analysis, and finally analyzed the reliability of the system. In order to improve the reliability of the system, it is necessary to optimize the equipment maintenance further [3]. Lhorente analyzed the fault data, estimated the fault distribution of the equipment using the three-parameter Weibull distribution model, comprehensively considered the impact of preventive maintenance and fault maintenance of the equipment, and then determined the shortest maintenance cycle of the equipment under the condition of optimal investment cost of the equipment [4]. Barabady decomposed the crusher system into six subsystems, fitted the collected data, obtained the fault distribution model of each subsystem, and

\footnotetext{
* Corresponding author.

E-mail address: 1013137639@qq.com
} 
determined the reliability of each subsystem and the reliability of the crusher system. [5]. Elevli established the maintenance function of the equipment. By analyzing the reliability of the equipment, the maintenance cycle of the equipment was determined, and the maintenance cost and operation cost of the equipment were reduced [6]. Dai used the reliability theory to analyze the use status, reliability index, and fault law of coal mine equipment, scientifically specify the repair content, optimize the repair time, and classify the repair type. Relevant countermeasures such as age replacement, time maintenance, and regular maintenance to maximize system availability effectively improved the reliability of the equipment [7]. Hoseinie established a three-parameter Weibull distribution model for the coal cutter and conducted reliability analysis. Based on the reliability analysis, the interval time of equipment maintenance was determined [8]. According to the Bernbaum factor method and based on the shearer reliability of the shearer components, Gupta established a two-parameter Weibull distribution model based on the fault data and combined it with the fault tree to determine the failure rate function of the equipment. The degree of contribution was prioritized for the repair of various components of the shearer, and the maintenance strategy of the shearer was updated according to the sequencing situation [9]. Hoseinie established a reliability model based on the fault time for shearer failure and introduced the cost rate function to determine the best maintenance time of the shearer [10]. Dong proposed to establish an equipment maintenance system based on Internet of things technology for low levels of mine equipment management. It uses Internet of things technology for maintenance, but it cannot be accurately maintained due to the influence of underground environmental factors [11]. Petrovi believed that high-quality maintenance of mining equipment requires a thorough analysis of the components of the equipment to identify key components in a system that is prone to failure. Therefore, a technical system fault risk assessment model based on fuzzy set theory, fuzzy logic, and minimum-maximum combination was proposed, and equipment maintenance was carried out according to the results of risk assessment [12]. The underground environment of mines is complex and changeable, and it has a certain impact on the operating state of the equipment and affects the development of maintenance strategies for mining equipment. However, in existing literature on the maintenance of mining equipment, the selection of the failure rate distribution function of the equipment is directly given, and the parameter of the failure rate function is not estimated and corrected based on the operational history fault data information of the equipment and the impact of the mine environment. Aiming at this problem, this paper combines the least squares method and the correlation coefficient method to propose the equipment failure rate function based on the fault data, comprehensively evaluates the impact of environmental factors on the equipment, and uses fuzzy knowledge to correct the equipment's failure rate function. During the life cycle of the equipment, minor repairs are performed when the equipment fails, resulting in minor repair costs. In order to reduce the occurrence of equipment failure, enterprises carry out preventive maintenance on equipment, which results in preventive maintenance costs. Taking the above factors into consideration, the mathematical model for equipment maintenance is established to optimize the expected cost of the enterprise. The results of the final example show the effectiveness of the strategy and provide an effective equipment maintenance solution for mining enterprises.

\section{Basic Model}

Model hypothesis:

(1) Assume that the failure rate function is a function of the time parameter $t$.

(2) After the equipment fails, it will be repaired to make the equipment return to normal.

(3) The equipment maintenance time and cycle preventive maintenance time are ignored.

(4) Assume that the remaining life of the equipment is $L$.

\subsection{Failure Rate Function}

Due to the non-linearity of equipment fault data, it is assumed that the distribution model of equipment fault follows the Weibull distribution function with three parameters. Then, the failure rate function is

$$
\lambda(t)=\frac{\beta}{\eta} \times\left(\frac{t-\gamma}{\eta}\right)^{\beta-1}
$$

Where $t$ indicates time, $\gamma$ is the location parameter, $\eta$ is the scale parameter, and $\beta$ is the shape parameter.

The distribution function is

$$
F(t)=1-\exp \left[-\left(\frac{t-\gamma}{\eta}\right)^{\beta}\right]
$$




\subsection{Determination of Parameters of the Fault Rate Function}

The linear transformation of the three-parameter Weibull distribution function can be expressed as

$$
\ln \{-\ln [R(t)]\}=\beta \ln (t-\gamma)-\beta \ln (\eta)
$$

A set of fault intervals with a capacity of $n$, arranged in ascending order, is defined as $t_{1}<t_{2}<\cdots<t_{n}$.

In order to reduce the error, the reliability is estimated by the median rank method.

$$
R\left(t_{i}\right)=\frac{(i-0.3)}{(n+0.4)}
$$

Let $y_{i}=\ln \left\{-\ln \left[R\left(t_{i}\right)\right]\right\}, x_{i}=\ln t_{i}$ 。 The regression linear equation to be fitted is

$$
y=a x+b
$$

It can be determined from the principle of least square method [13] that the regression coefficients $a, b$ and correlation coefficient $R_{x y}$ are

$$
\begin{gathered}
b=\frac{l_{x y}}{l_{x x}}=\frac{\sum_{i=1}^{n}\left(x_{i}-\bar{x}\right)\left(y_{i}-\bar{y}\right)}{\sum_{i=1}^{n}\left(x_{i}-\bar{x}\right)^{2}} \\
a=\bar{y}-b \bar{x} \\
R_{x y}=\frac{l_{x y}}{\sqrt{l_{x x} l_{y y}}}
\end{gathered}
$$

The numerical iteration method is used to determine the estimated value of position parameter $\gamma$. Assuming that the position parameter $\gamma_{01}=\min \left\{t_{i}\right\}$ is the initial value of $\gamma$, calculate the corresponding correlation coefficient $R_{01}$. In the same way, calculate $R_{0 n}$ sequentially. When $\gamma$ is estimated correctly, there is a maximum correlation coefficient between $x$ and $y$, thereby determining the value of the positional parameter $\gamma$.

\subsection{Verification of Failure Rate Model}

The $d$ test compares the difference between the distribution function $F_{0}(t)$ corresponding to the fault interval data and the calculated value $F_{n}(t)$ corresponding to each fault interval. The maximum value of the absolute value of the difference is the observed value $D_{n}$, and then compare the value of $D_{n}$ with the critical value of $D_{n, \alpha}$. If $D_{n} \leq D_{n, \alpha}$, the fault data of the equipment conforms to the Weibull distribution model with three parameters. Otherwise, it does not.

\subsection{Failure Rate Function Correction}

\subsubsection{Main Environmental Factors}

The underground environment of coal mines is not ideal. Most of the mechanical equipment involved in the production process are affected by the factors of the underground environment and are easily damaged. At the same time, as the coal mining depth increases, the temperature and humidity also increase. This results in down-hole equipment heat dissipation 
failures, which lead to equipment failures. This paper mainly analyzes the temperature and humidity that affect the operating state of underground equipment.

(1) Temperature. Temperature has a direct effect on down-hole equipment. When mechanical equipment is running, a large amount of heat will be generated. If the heat diffusion is not timely due to the high down-hole temperature, the normal operation of the equipment will be affected, and mechanical failures will result.

(2) Humidity. The influence of humidity on down-hole equipment also plays a direct role. When the down-hole humidity is in the normal condition, the corrosion rate of the equipment is relatively slow, and when the humidity increases obviously, the corrosion of the equipment will accelerate, resulting in equipment failure. Large relative humidity of the ambient air promotes the growth of mold, which causes the equipment to stop operating [14].

\subsubsection{Fault Rate Correction based on Fuzzy Theory}

(1) The selection of membership function

The variation of down-hole environment has strong uncertain factors on the influence of equipment. Therefore, based on the long-term experience and historical data of down-hole workers, these types of environmental factors are judged, and the membership function is determined.

In the normal temperature and humidity range, the normal operation of the down-hole equipment is not affected, so the value is set to 0 . Too high or too low temperatures have a significant impact on the equipment, so the function value is set to 1. The membership function is shown in Figure 1, and the membership function is given as Equation (9).

$$
r(x)=\left\{\begin{array}{l}
1, x<c \\
\frac{a-x}{a-c}, c \leq x \leq a \\
0, a \leq x \leq b \\
\frac{x-b}{d-b}, b \leq x \leq d \\
1, x \geq d
\end{array}\right.
$$

Where $x$ indicates the temperature and humidity; $a, b, c, d$ are the threshold parameters corresponding to the variables; and $r(x)$ represents the influence factor corresponding to each factor. Less than the lower limit indicates that the influence is 0 . The upper limit threshold indicates that the influence is large, and the influence coefficient is 1 .

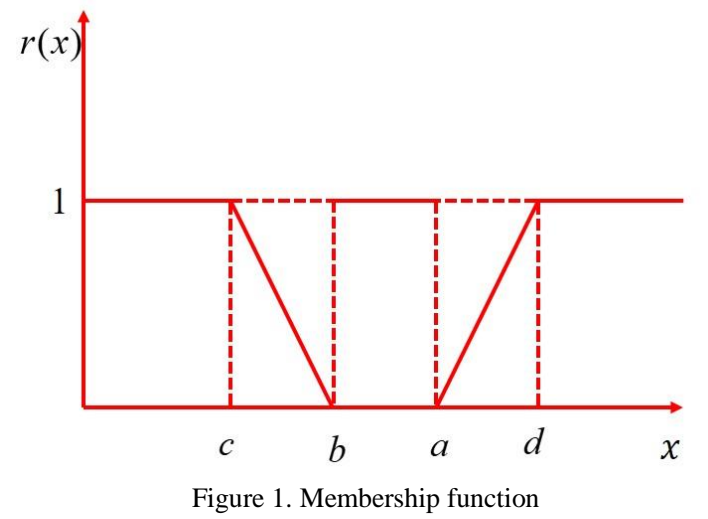

(2) Correction model for failure rate of down-hole equipment

Generally speaking, each equipment in the mine is not a single structure and is composed of multiple parts. The possible influence of the external environment on each part is different. Suppose the equipment consists of $n$ components, as shown in Equation (10). 


$$
S=[n]
$$

Where $S$ represents the whole equipment and $n$ represents the components.

Their fuzzy numbers are determined by the membership function expression of down-hole temperature and humidity influence factors [15], as shown in Equation (11).

$$
r=\left[r_{n 1}, r_{n 2}\right]
$$

Where $r_{n 1}$ and $r_{n 2}$ respectively represent the fuzzy number of influence factors of temperature and humidity on equipment component $n$, and the fuzzy matrix can be expressed as

$$
R=\left[\begin{array}{cc}
r_{11} & r_{12} \\
r_{21} & r_{22} \\
\vdots & \vdots \\
r_{n 1} & r_{n 2}
\end{array}\right]
$$

Where $r_{n j}$ represents the nth component of down-hole equipment affected by the down-hole external environment $j$. Definition $B=\left[b_{1}, b_{2}\right]$ refers to the weight coefficient of temperature and humidity on all parts of the equipment, and then

$$
A=B \times R^{\mathrm{T}}=\left[a_{1}, a_{2} \cdots a_{n}\right]^{\mathrm{T}}
$$

Where $a_{i}$ represents the comprehensive influence factor considering temperature and humidity on equipment component $n$. Then, the average influence factor of the whole equipment is expressed as

$$
\mu=\left(\sum_{i=1}^{n} a_{i} n_{i}\right) / \sum_{i=1}^{n} n_{i}
$$

The failure rate function of the equipment, which is calculated from the state of the equipment itself or the failure history data of the equipment, is $\lambda(t)$. The failure rate function is $\lambda_{x}(t)$ after the correction of the external environmental factors of the underground is $\lambda_{x}(t)$, that is,

$$
\lambda_{x}(t)=(1+\mu) \lambda(t)
$$

\subsection{Expected Total Cost}

Suppose the daily maintenance cost of equipment and the maintenance cost of equipment failure are respectively $C_{p}$ and $C_{m}$, where $a$ and $b$ are constants. Assuming that the remaining life cycle of the equipment is $L, T_{0}$ is the current preventive maintenance cycle, and $N$ is the number of maintenance times within the maintenance cycle, the total expected maintenance cost within the life cycle is

$$
C_{q}=\sum_{i=1}^{n} C_{p}+C_{m}\left[\sum_{k=1}^{N} \int_{0}^{T_{0}} \lambda_{x}(t) \mathrm{d} t+\int_{N T_{0}}^{L} \lambda_{x(N+1)}(t) \mathrm{d} t\right]
$$

According to the Weibull distribution property, parameter $\eta$ mainly affects the occurrence time of equipment failure rate, and the preventive maintenance only changes the value of $\eta$. Thus, $\eta$ is a function of maintenance cycle $T$, and $\eta=\eta(T)$. Suppose that the failure rate function $\lambda_{x}(t, T)$ is a function of the equipment failure rate under the maintenance cycle of $T_{0}$, and the failure rate function $\lambda_{x}(t, T)$ is related to $T_{0}$ [16-17]. Then, 


$$
\eta(T)=\eta \times\left(\frac{T_{0}}{T}\right)
$$

Where $T$ represents the maintenance cycle after optimization. If Equation (17) is substituted into the failure rate function of the three-parameter Weibull distribution, the following can be obtained:

$$
\lambda_{x}(t, T)=\left(\frac{T}{T_{0}}\right)^{\beta} \times \frac{(1+\mu) \beta}{\eta} \times\left(\frac{t-\gamma}{\eta}\right)^{\beta-1}
$$

$\lambda_{x}(t, T)$ and $\lambda_{x}(t)$ have the following relationship:

$$
\sum_{k=1}^{N} \int_{0}^{T_{0}} \lambda_{x}(t) \mathrm{d} t+\int_{N T_{0}}^{L} \lambda_{x(N+1)}(t) \mathrm{d} t=\int_{0}^{L} \lambda_{x}(t, T) \mathrm{d} t
$$

Based on the above, the total expected cost of underground equipment in the life cycle can be expressed as

$$
C_{q}=N C_{p}+C_{m} \int_{0}^{L} \lambda_{x}(t, T) \mathrm{d} t
$$

We can obtain

$$
C_{q}=N C_{p}+C_{m} \times(1+\mu) \times\left[\left(\frac{T}{T_{0}}\right)^{\beta} \times\left(\frac{L-\gamma}{\eta}\right)^{\beta}+\left(\frac{T}{T_{0}}\right)^{\beta} \times\left(\frac{\gamma}{\eta}\right)^{\beta}\right]
$$

\section{Optimal Preventive Maintenance Strategy}

Equation (21) is optimized to minimize the value of $C_{q}$, so as to obtain the optimal maintenance number $N^{*}$ and the optimal maintenance period $T^{*}$. In order to minimize $C_{q}$, the following theorems are given by observing Equation (21):

Theorem 1 When the number of preventive maintenances is $N$, the range of $T$ is $\left[\frac{L}{N+1}, \frac{L}{N}\right]$. The expected minimum cost is achieved at time $T=\frac{L}{N+1}$.

Based on Theorem 1, specific calculation steps are given:

Step 1 Set $N=2$.

Step 2 Calculate $T_{\min }=\frac{L}{N+1}$ and $C_{q}$.

Step 3 When $\lim N \rightarrow \lim N+1$, take any $\bar{N}$. If $N<\bar{N}$, take step 2. Otherwise, proceed to the next step.

Step 4 When searching for the value of $1<N<\bar{N}$, the minimum value of $C_{q}$ is the optimal expected total cost.

Step 5 Calculate the optimal maintenance cycle $T^{*}$ and the optimal maintenance number $N^{*}$.

\section{Case Analysis}

\subsection{Parameter Estimation}

As the main equipment for transporting coal in coal mines, belt conveyors play a vital role in the smooth operation of downhole production. Therefore, it is necessary to carry out reasonable maintenance on belt conveyors. The design production capacity of the $\mathrm{XX}$ coal mine is 1.2 million tons/year, and the main mode of coal transportation is by belt 
conveyor. Figure 2 shows the XX coal mine-980 strong belt conveyor. Due to frequent failures and improper maintenance, the normal operation of underground production is seriously affected.

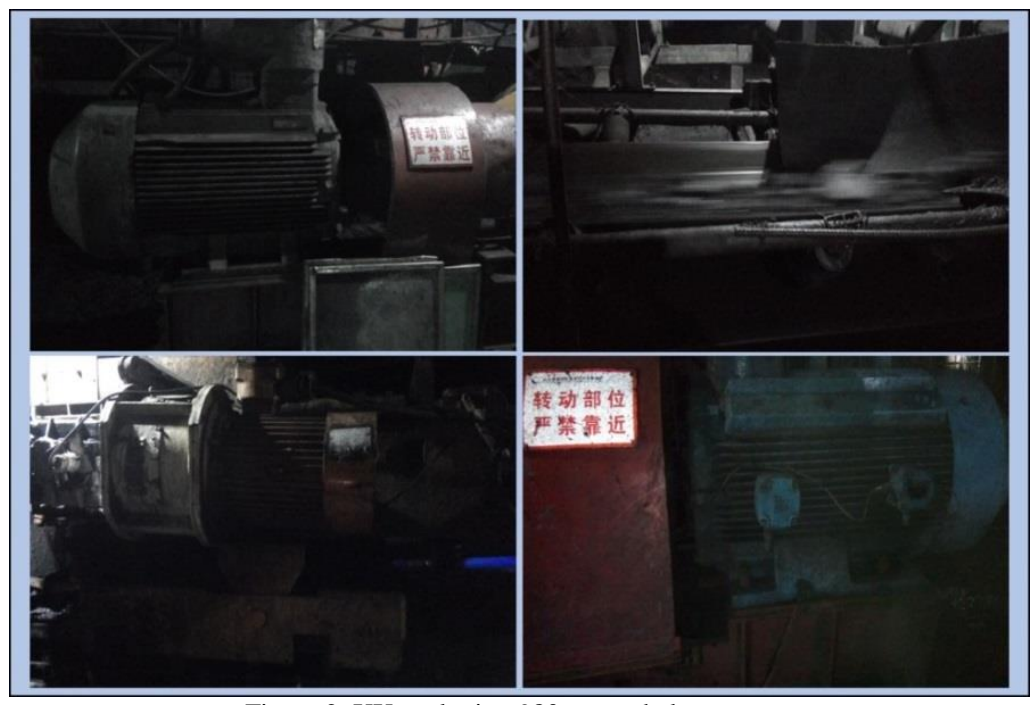

Figure 2. XX coal mine-980 strong belt conveyor

The fault data of the XX coal mine-980 strong belt conveyor is collated and brought into Equations (3) and (4) to obtain the belt conveyor breakdown interval time, as shown in Table 1.

Table 1. Breakdown interval time of the equipment

\begin{tabular}{|c|c|c|c|c|c|c|c|c|c|}
\hline NO. & $t_{i}$ & $R_{n}\left(t_{i}\right)$ & $x_{i}$ & $y_{i}$ & NO. & $t_{i}$ & $R_{n}\left(t_{i}\right)$ & $x_{i}$ & $y_{i}$ \\
\hline 1 & 0.5 & 0.01 & -0.69 & -4.47 & 32 & 61.17 & 0.50 & 4.12 & 30.00 \\
\hline 2 & 0.85 & 0.03 & 0.41 & -3.57 & 33 & 63.50 & 0.53 & 4.11 & -0.41 \\
\hline 3 & 1.5 & 0.04 & 0.77 & -3.10 & 34 & 64.52 & 0.55 & 4.12 & -0.37 \\
\hline 4 & 2.17 & 0.06 & 0.85 & -2.78 & 35 & 65.17 & 0.57 & 4.15 & -0.32 \\
\hline 5 & 2.33 & 0.08 & 1.05 & -2.53 & 36 & 69.60 & 0.58 & 4.17 & -0.27 \\
\hline 6 & 2.87 & 0.09 & 1.11 & -2.33 & 37 & 71.17 & 0.60 & 4.18 & -0.23 \\
\hline 7 & 3.03 & 0.11 & 1.99 & -2.16 & 38 & 79.45 & 0.61 & 4.24 & -0.18 \\
\hline 8 & 7.33 & 0.13 & 2.41 & -2.01 & 39 & 81.90 & 0.63 & 4.27 & -0.14 \\
\hline 9 & 11.17 & 0.14 & 2.45 & -1.88 & 40 & 91.00 & 0.65 & 4.38 & -0.09 \\
\hline 10 & 11.58 & 0.16 & 2.71 & -1.76 & 41 & 98.92 & 0.66 & 4.41 & -0.05 \\
\hline 11 & 15 & 0.17 & 2.83 & -1.65 & 42 & 104.42 & 0.68 & 4.51 & 0.00 \\
\hline 12 & 17 & 0.19 & 3.22 & -1.55 & 43 & 104.77 & 0.70 & 4.59 & 0.04 \\
\hline 13 & 25.12 & 0.21 & 3.24 & -1.46 & 44 & 109.33 & 0.71 & 4.65 & 0.08 \\
\hline 14 & 25.58 & 0.22 & 3.33 & -1.38 & 45 & 120.80 & 0.73 & 4.65 & 0.13 \\
\hline 15 & 27.95 & 0.24 & 3.40 & -1.30 & 46 & 122.05 & 0.74 & 4.69 & 0.17 \\
\hline 16 & 29.92 & 0.26 & 3.52 & -1.22 & 47 & 125.75 & 0.76 & 4.79 & 0.22 \\
\hline 17 & 33.78 & 0.27 & 3.54 & -1.15 & 48 & 132.50 & 0.78 & 4.80 & 0.26 \\
\hline 18 & 34.52 & 0.29 & 3.73 & -1.08 & 49 & 150.67 & 0.79 & 4.83 & 0.31 \\
\hline 19 & 41.5 & 0.30 & 3.77 & -1.01 & 50 & 161.97 & 0.81 & 4.89 & 0.36 \\
\hline 20 & 43.38 & 0.32 & 3.81 & -0.95 & 51 & 162.42 & 0.83 & 5.02 & 0.41 \\
\hline 21 & 44.93 & 0.34 & 3.82 & -0.89 & 52 & 178.83 & 0.84 & 5.09 & 0.45 \\
\hline 22 & 45.83 & 0.35 & 3.83 & -0.83 & 53 & 197.58 & 0.86 & 5.09 & 0.51 \\
\hline 23 & 45.93 & 0.37 & 3.84 & -0.77 & 54 & 259.00 & 0.87 & 5.19 & 0.56 \\
\hline 24 & 46.33 & 0.39 & 3.84 & -0.72 & 55 & 295.00 & 0.89 & 5.29 & 0.61 \\
\hline 25 & 46.5 & 0.40 & 3.99 & -0.66 & 56 & 330.28 & 0.91 & 5.56 & 0.67 \\
\hline 26 & 54.03 & 0.42 & 4.05 & -0.61 & 57 & 360.17 & 0.92 & 5.69 & 0.73 \\
\hline 27 & 57.12 & 0.43 & 4.07 & -0.56 & 58 & 412.60 & 0.94 & 5.80 & 0.80 \\
\hline 28 & 58.33 & 0.45 & 4.07 & -0.51 & 59 & 456.50 & 0.96 & 5.89 & 0.87 \\
\hline 29 & 58.5 & 0.47 & 4.11 & -0.46 & 60 & 582.02 & 0.97 & 6.02 & 0.94 \\
\hline 30 & 61 & 0.48 & 4.11 & -0.41 & 61 & 666.20 & 0.99 & 6.50 & 1.50 \\
\hline 31 & 61.33 & 0.52 & 4.11 & -0.46 & & & & & \\
\hline
\end{tabular}

From Equations (3)-(8), $\beta=b=0.82, a=-3.77$, and $\eta=e^{(-a / b)}=109.51$. According to the method of numerical iteration, $\gamma=0.4$ can be obtained. 


\section{2. $d$ Test}

The $d$ test compares the difference between the distribution function $F_{0}(t)$ corresponding to the fault interval time data of the belt conveyor and the calculated value $F_{n}(t)$ corresponding to each fault interval. The maximum absolute value of the difference is the observed value $D_{n}$. Then, $D_{n}$ and the critical value $D_{n, \alpha}$ are compared. If $D_{n} \leq D_{n, \alpha}$, the fault data of the belt conveyor conforms to the Weibull distribution model with three parameters; otherwise, it does not. Through calculation, $D_{n}=0.091$. In the $d$ test, based on experience, $D_{n, \alpha}=1.22 / \sqrt{n}=0.156>D_{n}$. Therefore, the hypothesis is established, and the fault interval time of the belt conveyor conforms to the Weibull distribution model with three parameters.

\subsection{Model Modification}

According to the statistical analysis, the critical value of the membership function that affects the temperature and humidity of the belt conveyor is shown in Table 2 .

The belt conveyor consists of six parts: a conveyor belt, roller, body frame, expansion cylinder, tightener device, and transmission device [18]. According to the measured data, the temperature and humidity of each part of the belt conveyor are shown in Table 3.

Table 2. Critical value of membership function

\begin{tabular}{|c|c|c|}
\hline \multicolumn{2}{|l|}{ Influence factors } & Critical value of membership function \\
\hline Temperature $\left({ }^{\circ} \mathrm{C}\right)$ & \multirow{2}{*}{\multicolumn{2}{|c|}{ 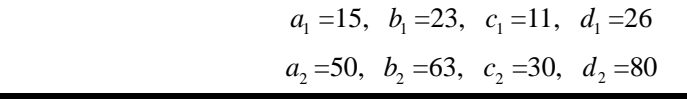 }} \\
\hline Humidity $(\%)$ & & \\
\hline Component of conveyor belt & Temperature $\left({ }^{\circ} \mathrm{C}\right)$ & Humidity (\%) \\
\hline Conveyor belt & 22 & 70 \\
\hline Roller & 23 & 60 \\
\hline Frame & 22 & 60 \\
\hline Drum & 24 & 56 \\
\hline Tightener & 23 & 60 \\
\hline Transmission device & 25 & 64 \\
\hline
\end{tabular}

The data in Table 3 is input into Equation (9) to get the fuzzy number of each influencing factor, as shown in Table 4.

Table 4. Fuzzy numbers of influencing factors

\begin{tabular}{ccc}
\hline Component of conveyor belt & Temperature $\left({ }^{\circ} \mathrm{C}\right)$ & Humidity $(\%)$ \\
\hline Conveyor belt & 0 & 0.412 \\
Roller & 0 & 0 \\
Frame & 0 & 0 \\
Drum & 0.5 & 0 \\
Tightener & 0 & 0 \\
Transmission device & 0.5 & 0.06 \\
\hline
\end{tabular}

Table 4 shows that

$$
R=\left[\begin{array}{cc}
0 & 0.412 \\
0 & 0 \\
0 & 0 \\
0.5 & 0 \\
0 & 0 \\
0.5 & 0.06
\end{array}\right]
$$


Based on the experience of field personnel, the weight of temperature and humidity is defined as $B=[0.55,0.45]$. Then, there is $A=B \times R^{\mathrm{T}}=[0.1854,0,0,0.275,0,0.302]^{\mathrm{T}}$, and $\mu=0.127$ can be obtained by Equation (14). Bring $\beta, \eta$, $\gamma$, and $\mu$ into Equation (21) to obtain the corrected belt conveyor failure rate function as

$$
C_{q}=N C_{p}+1.127 \times C_{m}\left[\left(\frac{T}{T_{0}}\right)^{0.82} \times\left(\frac{L-0.4}{109.51}\right)^{0.82}+0.01 \times\left(\frac{T}{T_{0}}\right)^{0.82}\right]
$$

\subsection{Optimization of Maintenance Policies}

It is known that the current maintenance cycle of the belt conveyor is $T_{0}=72 \mathrm{~h}$, and the preventive maintenance cost and minor repair cost of equipment are $C_{p}=80$ yuan and $C_{m}=500 \mathrm{yuan}$, respectively.

Assume that $L=50,400 \mathrm{~h}$. Bringing the parameter value into Equation (22) and calculating according to the algorithm given by Theorem 1, we can obtain the total expected cost of the equipment maintenance in the life cycle as $C_{q \min }=$ $378,942.44$ yuan. At this point, the optimal maintenance number is $N^{*}=2,133$, and the optimal maintenance cycle is $T^{*}=$ 23.64h. Figure 3 shows the value of the total expected cost $C_{q}$ of the equipment maintenance in the life cycle when $N$ takes different values.

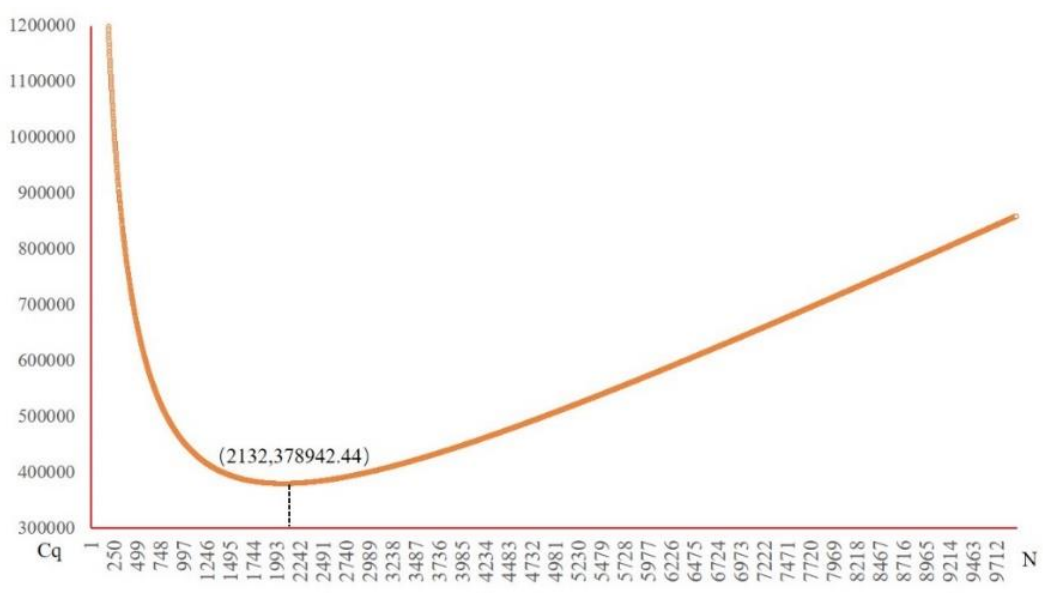

Figure 3. The value of different values of $C_{q}$ when $N$ takes different values

The current maintenance period of the belt conveyor is $T_{0}=72 \mathrm{~h}$, and it can be brought into Equation (22) to obtain the total maintenance cost of the equipment life cycle as $C_{q}=574,621$ yuan and the maintenance times $N=700$ times. Figure 4 shows the value of $C_{q}$ corresponding to $N=2,132$ and $N=700$. It can be seen that the maintenance cost can save 195,678.56yuan after optimization.

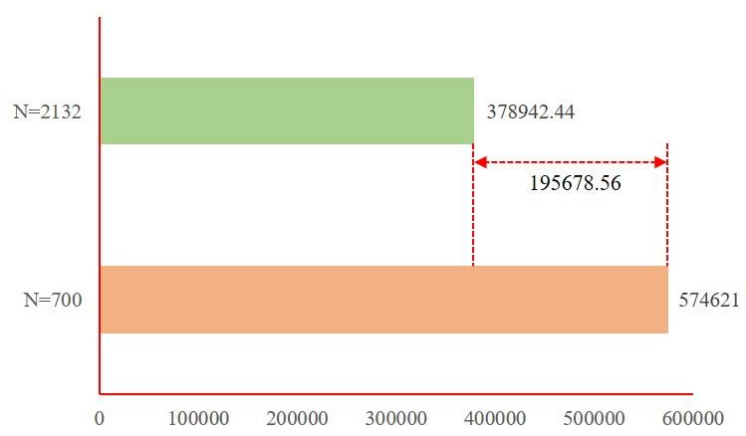

Figure 4. Comparison before and after optimization 
Figure 5 shows a case where the total maintenance cost of the equipment life cycle $C_{q}$ and the optimal maintenance times $N^{*}$ when the value of $L$ is different.

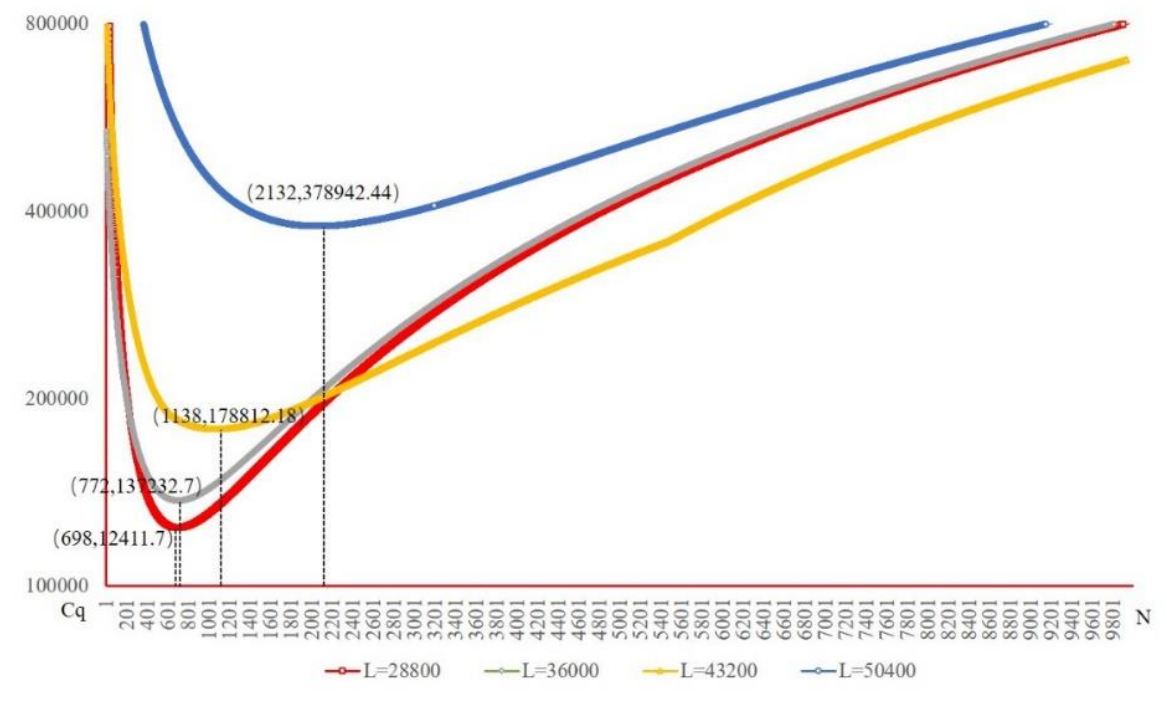

Figure 5. The value of $C_{q}$ and $N^{*}$

It can be seen from Figure 5 that the longer the remaining life cycle of the equipment, the greater the optimal maintenance time. At the same time, the expected total cost of maintenance increases during the life of the equipment, and equipment maintenance will become more frequent.

\section{Conclusions}

In order to solve the problem of improper maintenance and poor operating conditions of down-hole equipment in mining enterprises, this paper uses the historical fault data of the equipment, establishes the failure rate model, and considers the impact of the down-hole environment to correct the failure rate. From the perspective of enterprise cost, a periodic preventive maintenance strategy model for down-hole equipment of mining enterprises is proposed. Through research, the following conclusions are drawn:

(1) The current maintenance period of the belt conveyor is $T_{0}=72 \mathrm{~h}$, and the total maintenance cost in the life cycle of the equipment is $C_{q}=574,621$ yuan. The equipment maintenance period is optimized based on the enterprise cost. The optimized maintenance period is $23.64 \mathrm{~h}$, and the equipment maintenance activities will be more frequent. The total expected cost of maintenance during the life cycle is $C_{q}=378,942.44$ yuan, saving 195,678.56yuan of maintenance funds. The periodic preventive maintenance strategy model of the downhole equipment mentioned in this paper can effectively solve the equipment maintenance problem.

(2) When the remaining life cycle of the equipment increases, the time of maintenance of the equipment increases, the maintenance cycle becomes shorter and shorter, and the total expected maintenance cost of the coal enterprise equipment increases.

The above research provides an effective method for coal enterprises to properly carry out equipment maintenance and reduce equipment maintenance costs. It also provides theoretical guidance for actual production and an effective solution for the maintenance of underground equipment.

\section{References}

1. N. Vagenas, N. Runciman, and S. R. Clement, “A Methodology for Maintenance Analysis of Mining Equipment," International Journal of Surface Mining Reclamation and Environment, Vol. 11, No. 1, pp. 33-40, 1997

2. B. Samanta, B. Sarkar, and S. K. Mukherjee, "Mukherjee Reliability Analysis of Shovel Machines Used in an Open Cast Coal Mine," Mineral Resources Engineering, Vol. 10, No. 2, pp. 219-231, 2012 
3. R. A. Hall and L. K. Daneshmend, "Reliability Modeling of Surface Mining Equipment: Data Gathering and Analysis Methodologies," International Journal of Surface Mining Reclamation and Environment, Vol. 17, No. 3, pp. 139-155, 2003

4. B. Lhorente, D. Lugtigheid, and P. F. Knights, "A Model for Optimal Armature Maintenance in Electric Haul Truck Wheel Motors: A Case Study," Reliability Engineering and System Safety, Vol. 84, No. 2, pp. 209-218, 2004

5. J. Barabady, "Reliability and Maintainability Analysis of Crushing Plants in Jajarm Bauxite Mine of Iran," in Proceedings of Annual Reliability and Maintainability Symposium, pp. 109-115, 2005

6. S. Elevli and N. Uzgoren, "Maintainability Analysis of Mechanical Systems of Electric Cable Shovels," Journal Ofentific and Industrial Research, Vol. 67, No. 4, pp. 267-271, 2008

7. J. X. Dai, "Failure Rules and Preventive Countermeasures of Coal Mine Equipment System," Coal Science and Technology, Vol. 39, No. 1, pp. 72-74+79, 2011

8. S. H. Hoseinie, M. Ataei, and R. Khalokakaie, "Reliability Analysis of Drum Shearer Machine at Mechanized Longwall Mines," Journal of Quality in Maintenance Engineering, Vol. 18, No. 1, pp. 98-119, 2012

9. S. Gupta, N. Ramkrishna, and J. Bhattacharya, "Replacement and Maintenance Analysis of Longwall Shearer using Fault Tree Technique," Mining Technology, Vol. 115, No. 2, pp. 49-58, 2013

10. S. H. Hoseinie, B. Ghodrati, and D. Galar, "Optimal Preventive Maintenance Planning for Water Spray System of Drum Shearer," Ifac Papersonline, Vol. 48, No. 17, pp. 166-170, 2015

11. D. Li, M. Y. Ren, and G. Y. Meng, "Application of Internet of Things Technology on Predictive Maintenance System of Coal Equipment," Procedia Engineering, Vol. 174, pp. 885-889, 2017

12. D. V. Petrovi, M. Tanasijevi, and V. Mili, "Risk Assessment Model of Mining Equipment Failure based on Fuzzy Logic," Expert Systems with Applications, Vol. 41, No. 18, pp. 8157-8164, 2014

13. L. F. Zhang, M. Xie, and L. C. Tang, "A Study of Two Estimation Approaches for Parameters of Weibull Distribution based on WPP," Reliability Engineering and System Safety, Vol. 92, pp. 360-368, 2007

14. J. Li, L. Chen, and D. Zhao, "The Study of Overhead Line Fault Probability Model based on Fuzzy Theory," Energy and Power Engineerng, Vol. 5, No. 4, pp. 625-629, 2013

15. V. H. Coria, S. Maximov, and F. Rivas-Dávalos, "Analytical Method for Optimization of Maintenance Policy based on Available System Failure Data,” Reliability Engineering and System Safety, Vol. 135, pp. 55-63, 2015

16. C. L. Melchor-Hernández, F. Rivas-Dávalos, and S. Maximov, "A Model for Optimizing Maintenance Policy for Power Equipment," International Journal of Electrical Power and Energy Systems, Vol. 68, pp. 304-312, 2015

17. C. L. Melchor-Hernández, F. Rivas-Dávalos, and S. Maximov, "An Analytical Method to Estimate the Weibull Parameters for Assessing the Mean Life of Power Equipment," International Journal of Electrical Power and Energy Systems, Vol. 64, pp. 1081-1087, 2015

18. B. W. Li, L. R. Wan, and G. Y. Chai, "Mining Machinery,” China University of Mining Press, Xuzhou, 2010 